\title{
Trans-ionospheric GPS signal delay gradients observed over mid-latitude Europe during the geomagnetic storms of October-November 2003
}

\author{
S. M. Stankov ${ }^{*}$, R. Warnant, K. Stegen \\ Royal Meteorological Institute (RMI), Ringlaan 3, B-1180 Brussels, Belgium \\ *Corresponding author.Tel.: +32 60395 472; Fax: +3260395 423; E-mail: S.Stankov@ meteo.be
}

\begin{abstract}
Ionospheric disturbances are known to have adverse effects on the satellite-based communication and navigation. One particular type of ionospheric effects, observed during major geomagnetic storms and threatening the integrity performance of both ground-based and space-based GNSS augmentation systems, is the sharp increase/decrease in the ionospheric delay that propagates in horizontal direction, thus called for convenience 'moving ionospheric wall'. This paper presents preliminary results from researching such anomalous ionospheric delay gradients at European middle latitudes during the storm events of 29 October 2003 and 20 November 2003. For the purpose, 30-second GPS data from the Belgian permanent network was used for calculating and analysing the slant ionospheric delay and total electron content values. It has been found that, during these two particular storm events, substantial gradients did occur in Europe although they were not so pronounced as in the American sector.
\end{abstract}

Keywords: GNSS, GBAS, SBAS, aircraft navigation, ionospheric storm, ionospheric irregularity

\section{Introduction}

Satellite navigation uses GNSS (Global Navigation Satellite System) satellite broadcasts to calculate position; however, although possessing many advantages above the conventional navigation aids, the satellite-based navigation is prone to ionospheric effects. When electromagnetic signals traverse the ionosphere, the free electrons cause a delay in comparison to the same signal travelling through 'ionosphere-free' space. Such a delay induces an error on the computed position, which error is highly variable, difficult to model, and predict. The differential Global Positioning System (DGPS) approach to correcting for the ionospheric delay is based on carrier-smoothed code observables and uses a network of fixed, ground-based reference stations to broadcast the difference between the positions indicated by the satellite systems and the known fixed positions. The underlying premise is that any two receivers that are close together would experience similar errors. Thus, for a given satellite $i$ and a receiver $u$, the code measurement performed by the user is affected by an ionospheric error $I_{u}^{i}$ (also called ionospheric slant delay) which to a good approximation is given by $I_{u}^{i}=\frac{K}{f^{2}} T E C_{u}^{i}$. In this formula, $I_{u}^{i}$ is the error in metres, $\mathrm{K}$ is a constant (equal to $40.3 \mathrm{~m}^{3} / \mathrm{s}^{2}$ ), $f$ is the carrier frequency of the signal (in $\mathrm{Hz}$ ), and $T E C_{u}^{i}$ is the total electron content (TEC), i.e. the integral of the electron density along the satellite-to-receiver ray path. TEC is usually measured in terms of TEC units (TECU), where one TECU corresponds to $1 \times 10^{16}$ electrons per square metre and, at the GPS L1 frequency of $1.57542 \mathrm{GHz}$, is equivalent to a delay of 0.542 nanoseconds (i.e. to a path length increase of $0.163 \mathrm{~m}$ ). Simultaneously, the code measurement made at a reference station $r$ and the same satellite $i$, is affected by an ionospheric error, $I_{r}^{i}=\frac{K}{f^{2}} T E C_{r}^{i}$. In fact, the reference station provides the value of $I_{r}^{i}$ as a correction to be applied by the user. It is clear that the quality of the 
differential ionospheric correction will depend on the difference, $I_{u}^{i}-I_{r}^{i}$, between the ionospheric slant delays experienced by the user and the reference station (Klobuchar, 1996; Hofmann-Wellenhof et al., 2008). To enhance the quality of the DGPS correction and integrity information, particularly for real-time applications such as aircraft navigation, the Ground Based Augmentation System (GBAS) and the Space Based Augmentation System (SBAS) have been developed. Analogue version of GBAS is the US Local Area Augmentation System (LAAS) (Braff, 1998), and similar versions of the SBAS sysem are the US Wide Area Augmentation System (WAAS) $(F A A, 2001)$, the European Geostationary Navigation Overlay Service (EGNOS) (Ventura-Traveset and Flament, 2007), and Japan's Multi-Functional Satellite Augmentation System (MSAS).

Many applications (e.g. the aircraft precision vertical guidance), require precise correction and bounding of the ionospheric delay errors. The task is complicated by the ever-changing ionospheric dynamics, characterized by substantial variations in the vertical and horizontal electron density distribution that depends on solar/geomagnetic activity, season and local time (Akasofu and Chapman, 1972; Davies, 1990; Hargreaves, 1992). Delays tend to be larger at higher solar activity, larger around the equinoxes, and larger during the day than at night. Additionally, strong ionospheric disturbances, occurring as a result of solar events (e.g. solar flares) leading to geomagnetic storms, are capable of inducing large variability in the ionospheric delays, thus posing a real threat to aircraft precise positioning/navigation (Blanch et al., 2001; Luo et al., 2003). Ionospheric storms, and the associated ionospheric spatial and temporal gradients, may also lead to Network RTK (Real Time Kinematic) performance degradation (Stankov and Jakowski, 2007). It should be mentioned that horizontal ionospheric gradients in general are known to affect other GNSS applications too, these including dual frequency users where higher-order effects need to be mitigated in pursue of very high precision (Strangeways, 2000). In the case of LAAS, dual-frequency techniques can deliver robustness against ionospheric temporal gradients; however, since the raw-code ionospheric delay remains in the smoothed measurements, large ionospheric spatial gradients still pose a threat (Konno et al., 2006).

Anomalous ionospheric spatial gradients, characterized with sharp increase/decrease in ionospheric delays over relatively short horizontal distance are of particular concern considering their sudden appearance, like a wave with a steep front (or in other popular words, like a moving 'ionosphere wall'), their relatively fast propagation and changing behavioural patterns. The concern is due to the worst-case scenarios suggesting that such 'walls' might actually escape detection and thus cause integrity failures. For example, in the case of a GBAS-equipped airport, a situation may occur when the ionospheric wave front may come from behind an aircraft (approaching the airport for landing) and overtake this aircraft while also crossing one or more GPS-to-aircraft signal ray paths. In this way, a differential range error builds up until the wave front passes over the GBAS ground facility (Luo et al., 2004). Actually, the 'moving ionosphere wall' phenomenon was originally discovered with WAAS post-processed and bias-corrected (a.k.a. 'supertruth') data obtained during ionospheric storms of the recent solar activity maximum (Blanch et al., 2001; Walter et al., 2001; Datta-Barua et al., 2002; Luo et al., 2002, 2003). Exemplary results from the geomagnetic storm of 6 April 2000 are given in Fig.1. Similar features were also observed for the storms on 29 October 2003 and 20 November 2003 (Dehel et al., 2004). Such potentially hazardous ionospheric effects are not yet fully investigated and/or understood.

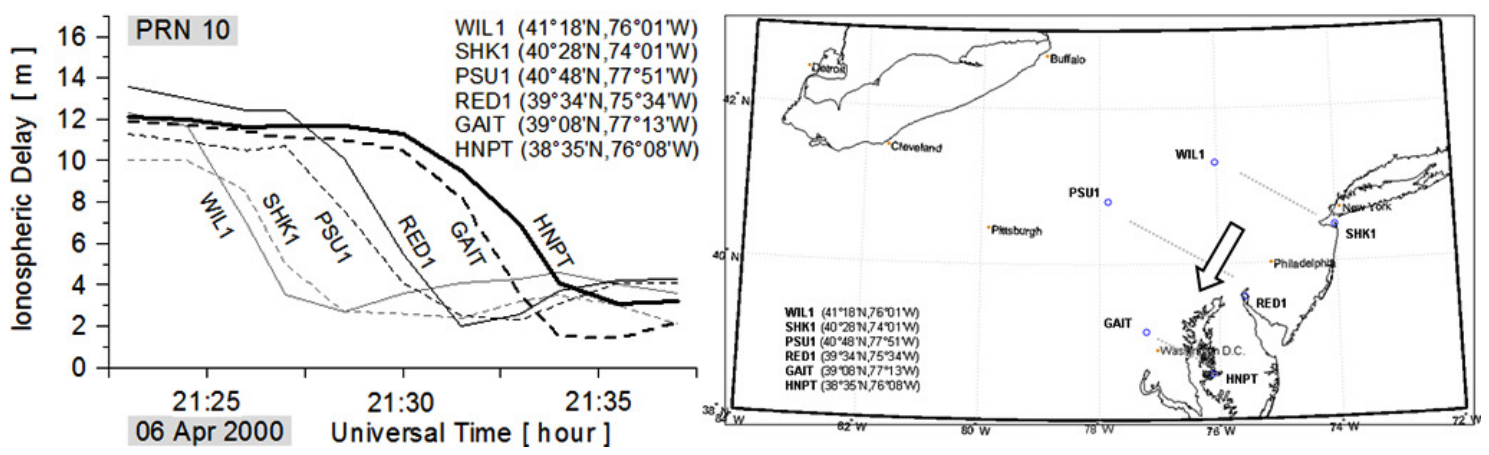

Fig.1. The geomagnetic storm on 6 April 2000. Ionospheric delay gradients (left) moving through multiple sites in the Washington DC area (right). (Source: Dehel et al., 2004; US National Geodetic Survey). 
This paper summarizes our observation of anomalous ionospheric delay behaviour in Europe and our preliminary research on the 'moving ionosphere wall' phenomenon. Comparisons have been made with corresponding American observations during the storms of 29 October and 20 November 2003.

\section{Case studies}

GPS code and phase dual frequency measurements can be used to reconstruct the slant TEC in the direction of all satellites in view from a given GPS station. For the purpose of studying ionospheric gradient anomalies, we have used GPS data, at a 30-second sampling rate, from the Belgian permanent network of about 70 GNSS stations. However, a smaller selection of stations is used here (Fig.2, left), namely BRUS $\left(50^{\circ} 47^{\prime} \mathrm{N}, 04^{\circ} 21^{\prime} \mathrm{E}\right)$, DENT $\left(50^{\circ} 56^{\prime} \mathrm{N}, 03^{\circ} 23^{\prime} \mathrm{E}\right)$, BREE $\left(51^{\circ} 08^{\prime} \mathrm{N}\right.$, $\left.05^{\circ} 38^{\prime} \mathrm{E}\right)$, WARE $\left(50^{\circ} 41^{\prime} \mathrm{N}, 05^{\circ} 14^{\prime} \mathrm{E}\right)$, and DOUR $\left(50^{\circ} 05^{\prime} \mathrm{N}, 04^{\circ} 35^{\prime} \mathrm{E}\right)$, chosen because of their location and distribution, suitable for researching the targeted phenomenon and for adequate comparison with the US results. Each station is assigned a unique symbol/line (and/or colour code) which will be used when plotting the measurements made at this station. GPS measurements have been processed using a technique developed by Warnant et al. (2000) and assuming the standard thin shell model, i.e. the entire ionospheric electron density is assumed concentrated in a very thin shell at a fixed height (e.g. $350 \mathrm{~km})$. Each ionospheric GPS measurement is represented by a location in this shell called Ionospheric Piercing Point (IPP) which is the intersection of the GPS signal ray path (from the satellite to the ground reference station) with the thin shell (Davies, 1990; Leitinger, 1996).
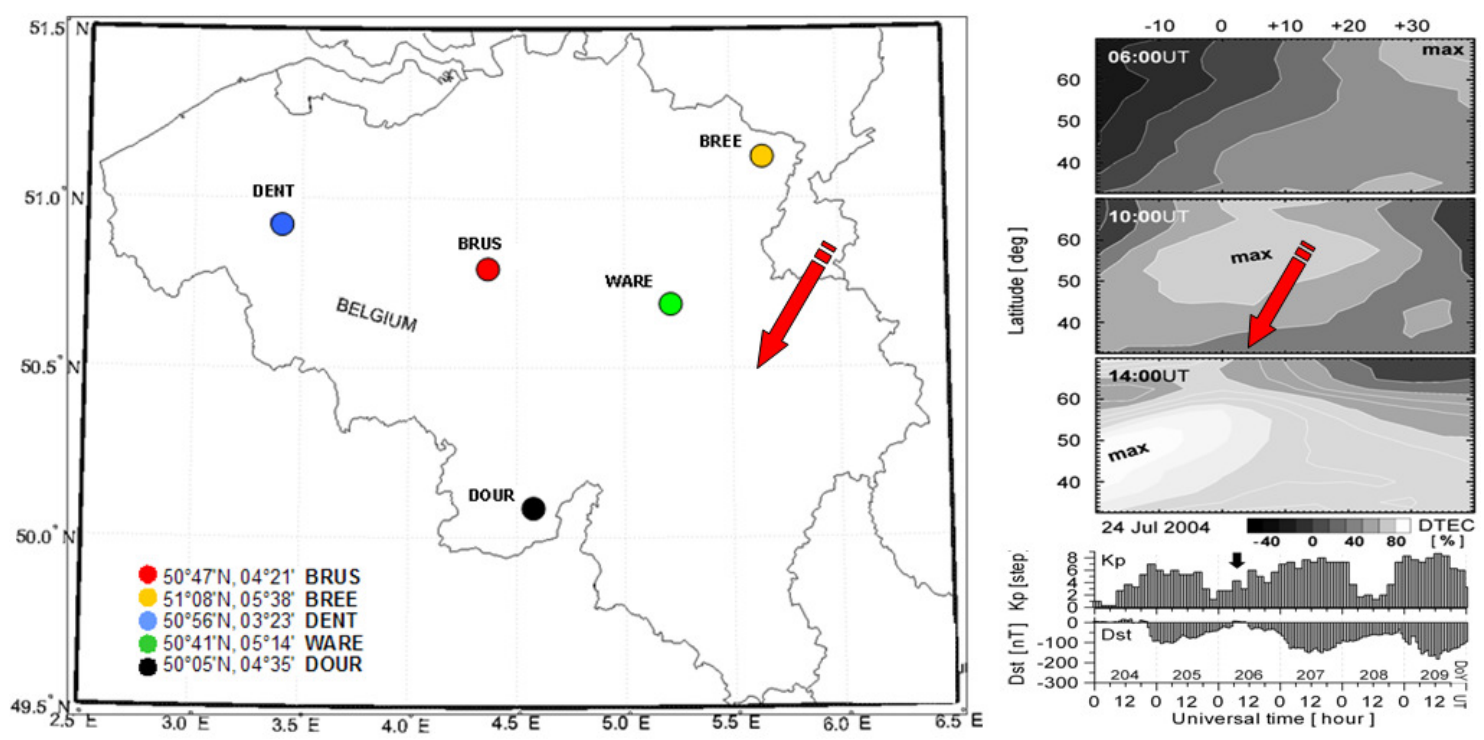

Fig.2. Left: Map of Belgium with the GPS stations used for this study. Right: Maps of the relative TEC deviation (dTEC, in percentage terms) from the corresponding monthly median values observed during the storm of 24 July 2004. Notice the NNE-SSW propagation pattern of the ionospheric disturbances.

Although data from all the selected stations were processed and analysed, mostly the measurements from the BREE-WARE-DOUR set of stations is of particular interest to us in this study and will be presented in more detail. These three stations were selected because of their geographic locations -- optimal distance from one another and alignment -- suitable for detection of the ionospheric disturbances and anomalies we are focused on in this paper. Such selection is well justified, considering the typical propagation patterns of ionospheric disturbances during storms in NNE-SSW direction. To demonstrate this propagation pattern, the TEC relative deviation from its monthly median value is calculated over a grid covering the European area. For a given grid point's location and time, the relative deviation $T E C_{r e l}$ (interchangeably, dTEC) is calculated by subtracting the monthly median value, $T E C_{\text {med }}$, from the measured value, $T E C_{m e s}$, and dividing the difference 
by the $T E C_{m e d}$ value, i.e. $T E C_{r e l}=\left(T E C_{m e s}-T E C_{m e d}\right) / T E C_{m e d}$. The median value is computed from the sample consisting of the $T E C_{\text {mes }}$ values obtained for the same hour and location within a month-long period centred at this particular time. $T E C_{r e l}$ is widely used in the ionospheric research as it enhances the ionospheric perturbation effects and facilitates the interpretation. For convenience, the $T E C_{r e l}$ value may be displayed in percentage terms like in the here-provided example of a typical ionospheric storm development (Fig.2, right). The observed increase of dTEC between 06:00UT and 14:00UT appears first in the northern high latitudes and then propagates steadily in equatorward direction. The development and propagation of such an increase is explained with the action of an eastward directed electric field which penetrates from high latitudes toward lower latitudes and thus lifts up the plasma via the electromagnetic $(\mathrm{E} \times \mathrm{B})$ drift effect, resulting in a reduced loss rate, that is, in a positive dTEC response (Stankov et al., 2006). In fact, the moving 'ionospheric walls' detected in the American sector during the storms in April 2000, October 2003, and November 2003, follow the above-described propagation pattern.

\subsection{The ionospheric storm on 29 October 2003}

In October 2003 the geomagnetic activity was relatively low except during the last three days when a large storm took place. The events at the end of October 2003 were characterized by a series of large radiation bursts at the Sun and huge coronal mass ejections (CMEs) causing severe perturbations in the geomagnetic field and in the geo-plasma environment formed by the magnetoand ionosphere. On 28 October, while the sunspot group 486 faced directly toward Earth, a huge solar flare was observed which was the third largest on record since 1976. The corresponding CME left the sun at about $2000 \mathrm{~km} / \mathrm{s}$ reaching the Earth magnetosphere in about 19 hours, around 06:00UT on 29-th October. The subsequent geomagnetic storm was one of the largest in the past 40 years continuing well into $30^{\text {th }}$ and $31^{\text {-st }}$ of October. For most of the time on 29 October the recorded planetary geomagnetic index $\mathrm{Kp}$ was close to its maximum possible value, indicating severe geomagnetic and ionospheric conditions (Fig.4, bottom). Similarly, the other geomagnetic index, Dst, strongly related to the magnetospheric parameters, reached values of about $-400 \mathrm{nT}$, thus confirming the extreme intensity and duration of the magnetic storm. These conditions set the background for observing and experiencing strong ionospheric effects.
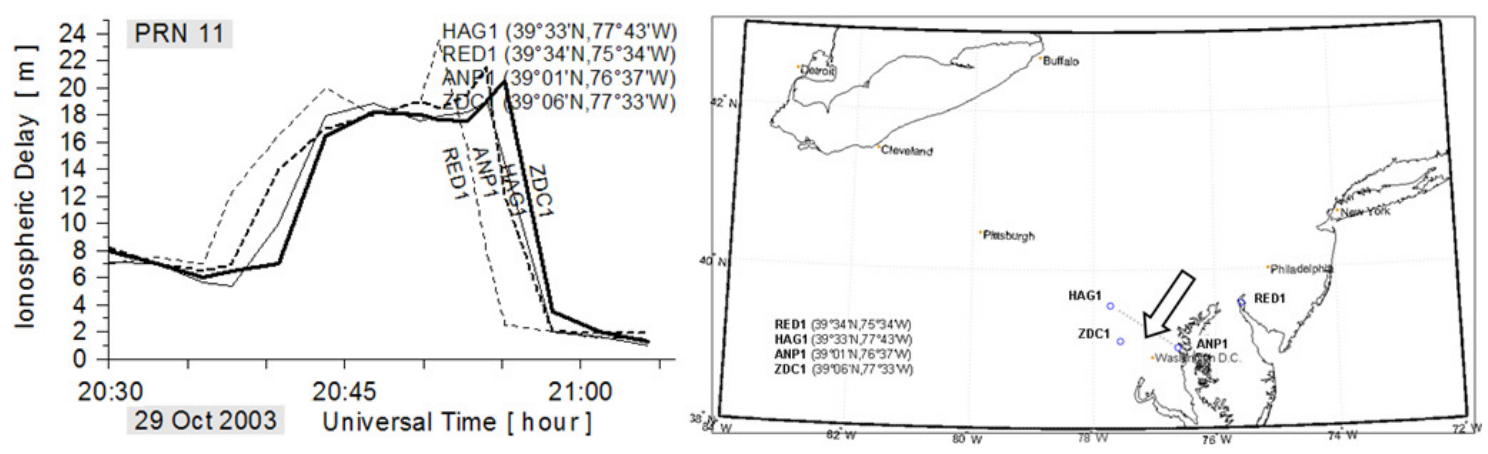

Fig.3. The geomagnetic storm on 29 October 2003. Large ionospheric delay gradients ('ionospheric walls') (left) observed among CORS clusters in the Washington DC area (right). (Source: Dehel et al., 2004; US National Geodetic Survey)

During the storm period of 29-31 October 2003, reported were several significant malfunctions due to the adverse effects of the ionosphere perturbations such as interruption of the WAAS service and degradation of mid-latitudes GPS reference services. Analyses of this storm using stations from the CORS (Continuously Operating Reference Stations) network in USA revealed steep ionospheric walls (sharp depletion) (Fig.3) moving through with high speeds and gradients of hundreds of $\mathrm{mm} / \mathrm{km}$ (Dehel et al., 2004). A simple way to determine the direction of the wall movement is by comparing the delay vs. time profiles from several stations. Thus, the almost identical profiles at HAG1 and 
ANP1 suggest that the wall passed over those two stations at the same time -- in a SW direction perpendicular to the HAG1-ANP1 line. The movement is similar to that in the previous case of 6 April 2000 (Fig.1) when the pairs WIL1-SHK1, PSU1-RED1, and GAIT-HNPT were consecutively passed over.

As already stated, it will be interesting to see if similar anomalies are observed here in Europe. For the purpose, we have analysed all available observations carried out at the selected network of GPS stations in Belgium during this particular ionospheric storm. The ionospheric delay measurements from 29 October 2003 deduced from all satellite links on this day are plotted in the top panel of Fig.4 with references to the corresponding ionospheric piercing points (IPP) given in the middle panel. The figure clearly shows the sharp increase of the ionospheric delay during the main phase of the storm in the morning hours. This increase is sustained well into the afternoon hours in accordance to the extreme geomagnetic activity conditions. It is followed by a significant drop of the delay in the period between 17:00UT and 20:00UT; hence, it is more likely to observe occurrences of 'ionospheric walls' within this time period.

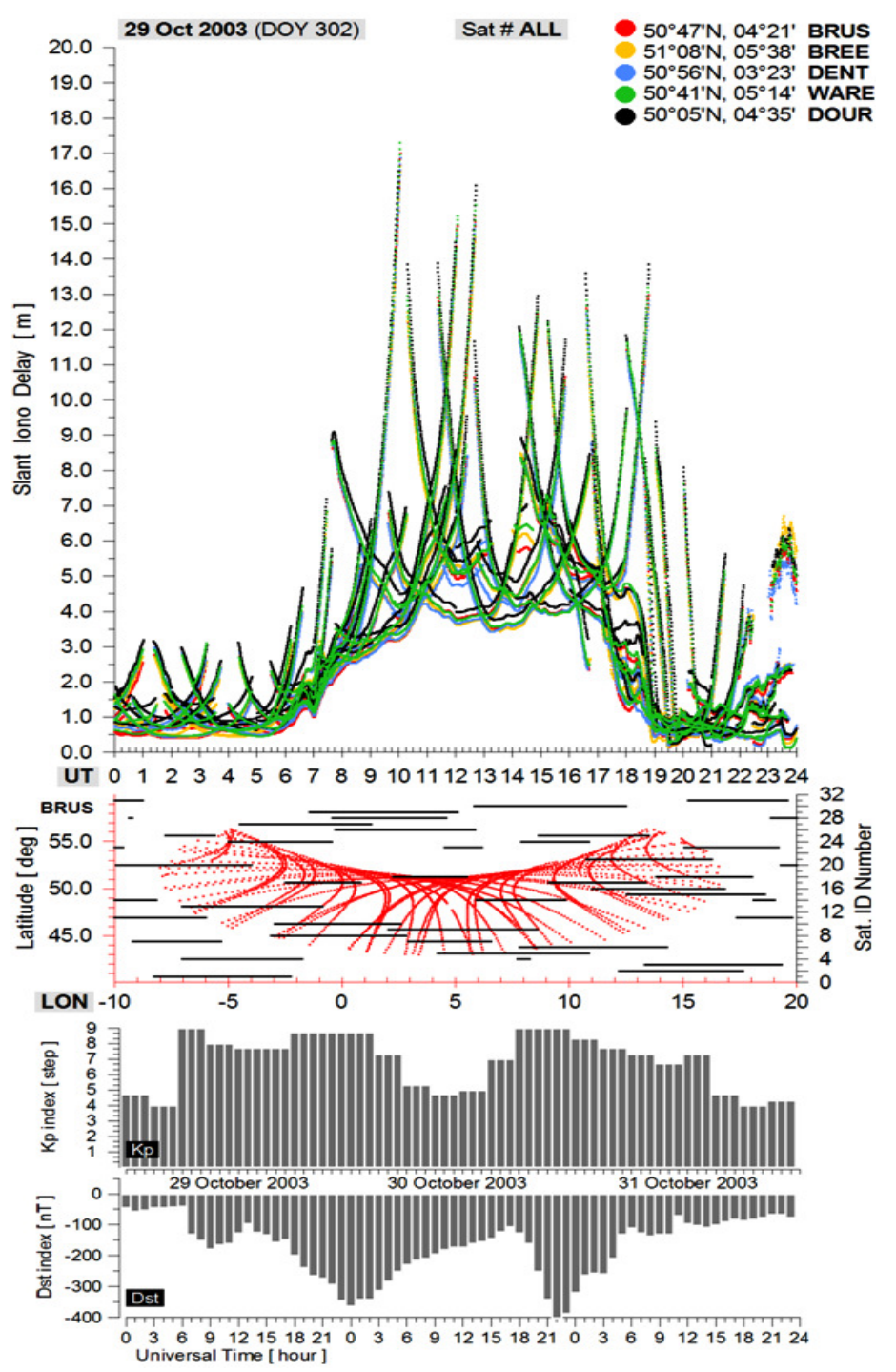

Fig.4. The geomagnetic storm on 29 October 2003. Top panel: Ionospheric delays measured via the GPS satellites 'visible' from the selected GPS stations in Belgium. Middle panel: The satellite IPP traces over Europe, with reference to the base reference station BRUS, plotted with dotted curves (red colour). The UT period of 'visibility' of each GPS satellite, again with reference to the BRUS station, plotted with solid lines (black colour). Bottom panel: The ionospheric storm background as represented by the planetary geomagnetic indices Kp and Dst. 
The figure also suggests that a proper detection and analysis of 'ionospheric walls' will have to deal with various inconveniences, such as the irregular coverage of the satellite IPP traces, different shape and orientation of these traces, short-term visibility of GPS satellites, etc. The majority of the slant ionospheric delay profiles, obtained from a satellite link, appear in the U-type shapes (Fig.5, left panel). The ionospheric effects are much smaller when the satellite is overhead and become greater and greater as the satellite nears the horizon because the signal is affected for a longer time. Thus, the increases in both ends can be explained with the effect of the gradually decreasing satellite elevation angle (hence increasing slant delay) combined with the effect of latitudinal and/or zonal gradients in the ionospheric density. Such combination of conditions seriously impedes the analysis. In the case presented for satellite \#5, the IPP traces have relatively small latitudinal resolution and large longitudinal coverage. As a result, what we see is a negligible latitudinal gradient except in the middle of the time period, i.e. between 13:00UT and 15:00UT when the IPPs positions are close to the GPS stations. Obviously, a gradual decrease of the electron density occurs in latitude direction, with higher values at the southern station DOUR and lower values in the northern stations WARE and BREE. A longitudinal gradient seems to also occur with higher densities observed in the West. Another frequently observed situation is presented in the right-hand panel of Fig.5 (satellite \#16) when one part of the IPP trace has East-West orientation and the other one has North-South orientation. Thus, the former part enhances possible longitudinal gradient and the latter part enhances the latitudinal gradient. Again, the IPP trace section that is nearest to the GPS stations shows undoubtedly the largest delay differences between the observations from the different stations.

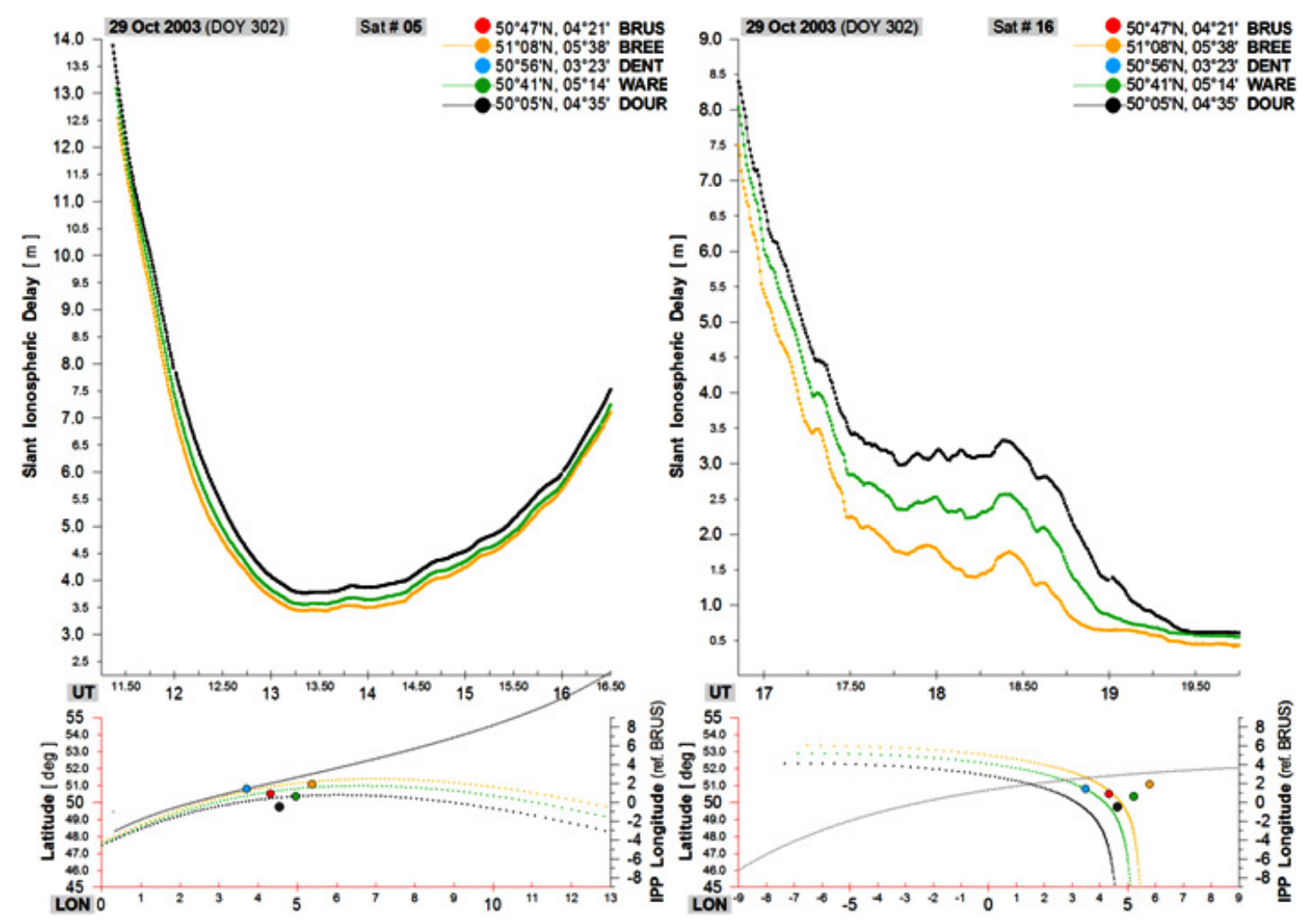

Fig.5. Top panels: Ionospheric delays during the storm of 29 October 2003 as measured via GPS satellites \#5 (left) and \#16 (right). Bottom panels: The satellite IPP traces (colour corresponding to station) on a geographic latitude vs. longitude map. The longitudinal excursion of the satellite IPP (ref. station BRUS) during the selected UT period is plotted with a solid line (grey colour).

Taking into account the above-presented concerns about the IPP trace location, shape, and orientation, hundreds of slant ionospheric delay profiles have been analysed for this storm. As expected, only a couple of profiles emerged from the period of interest, between 17:00UT and 
20:00UT, that suggest the occurrence of moving 'ionospheric walls' (Fig.6, top panels). The figure shows ionospheric delay drops suggesting an ionospheric density depletion that is moving in southward direction. The 'ionospheric walls' are somewhat similar in shape to the one observed in the April 2000 storm (Fig.1) but are different from the other one observed on 29 October 2003 in the Washington area (Fig.3). The ionospheric delay decrease in Europe appears to be less pronounced than the drop observed in the American sector. This observation can be explained with the differences in the geomagnetic latitude and local time between the corresponding events in the European and the American sectors. It is well known that the ionospheric phenomena are stronger bound to the geomagnetic coordinate frame rather than the geographic. Moreover, the ionospheric behaviour and the nature/magnitude of the ionospheric effects exhibit substantial spatial and temporal variations during both quiet and disturbed geomagnetic activity conditions (Akasofu and Chapman, 1972; Proelss, 1993; Fuller-Rowell et al., 1994, 1996; Szuszczewicz et al., 1998; Jodogne and Stankov, 2002).
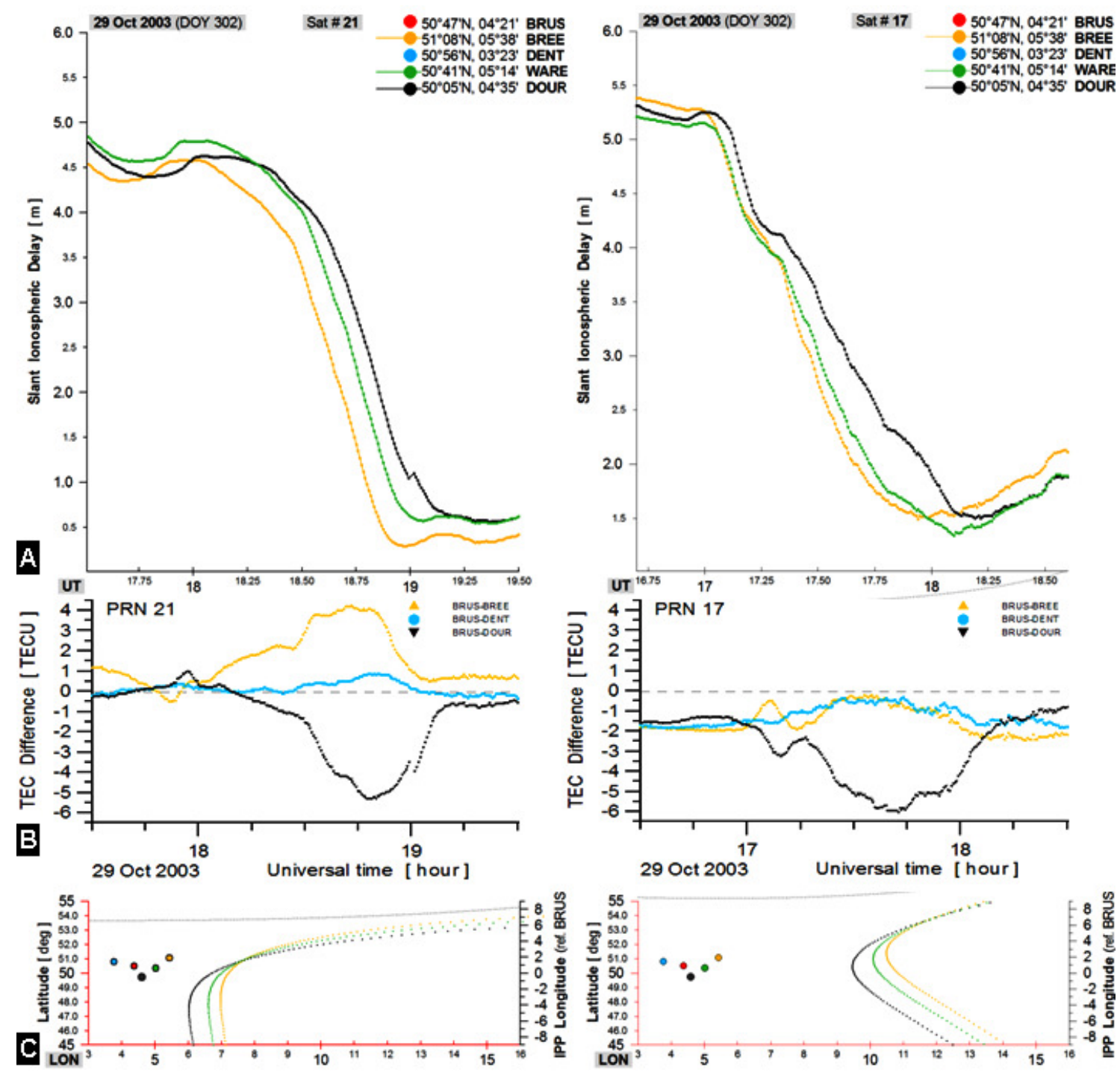

Fig.6. Top panels: Ionospheric delay gradients during the ionospheric storm of 29 October 2003 as measured via GPS satellites \#21 (left) and \#17 (right). Middle panels: Slant TEC differences between BRUS and three other stations. Bottom panels: The IPP traces (colour corresponding to station) on a geographic latitude vs. longitude map. 
To further analyse the observed difference let's have a more detailed look at the development of this particular storm. In principle, the geomagnetic storm impact is expected first on the high-latitude ionosphere because the latter is much stronger coupled with the magnetosphere and the solar wind. High-latitude electric fields, precipitation of energetic particles, and plasma convection, are reportedly the most powerful driving forces for the highly dynamic and complex processes in this region. During the onset phase of a storm, rapid ionization changes are generated over the polar regions leading to significant increase and variability of the plasma density. Thus, as already mentioned, large ionospheric plasma density gradients can be formed which propagate in equatorward direction. In the case of the geomagnetic storm of 29 October 2003, on the background of already increased TEC, a patch of higher ionisation was detected at about 07:00UT. The patch developed in size and moved southward over both the day-time and night-time hemispheres (Jakowski et al., 2005). The gradients are obviously larger in the sunlit hemisphere which explains the more pronounced ionospheric delay depletion in the American sector between 20:00UT and 22:00UT.

Further to our analysis of the ionospheric delay profiles, we have also calculated the slant TEC differences between the TEC values obtained at the reference station BRUS and the TEC values obtained at the other 3 stations (Fig.6, middle panels). The results, also obtained from measurements along links to satellites \#21 and \#17, are consistent with the just presented results for the ionospheric delays. The latitudinal gradients are clearly seen on the plots for DOUR and BREE. Since the latitudinal difference between BRUS and DENT is negligible, there is no significant difference in their measurements of the TEC. The TEC calculations from the BRUS station fulfil another important role -- that of determining the direction of the ionospheric wall movement. By selecting a central station (BRUS) surrounded by other suitably located stations in all possible directions, a star-like formation is set that can help to estimate, to a great level of precision, the direction of the ionospheric gradients propagation. For example, one can easily distinguish the almost flat curve representing the BRUS-DENT difference from the oppositely varying BRUS-BREE and BRUS-DOUR differences (Fig.6, middle left panel).

\subsection{The ionospheric storm on 20 November 2003}

A full halo coronal mass ejection (CME) associated with a relatively moderate, M-class, solar flare started on 18 November 2003. The CME, accompanied by a high-speed (about $700 \mathrm{~km} / \mathrm{s}$ ) solar wind and a strong southward component (about $60 \mathrm{nT}$ at $1 \mathrm{AU}$ ) of the interplanetary magnetic field (IMF), reached the Earth's magnetosphere on 20 November 2003, thus inducing the most intense geomagnetic storm of the current solar cycle. The geomagnetic storm commenced at 08:03UT and by 20:00UT the Dst index reached the -472 nT mark (Fig.8, bottom panels).

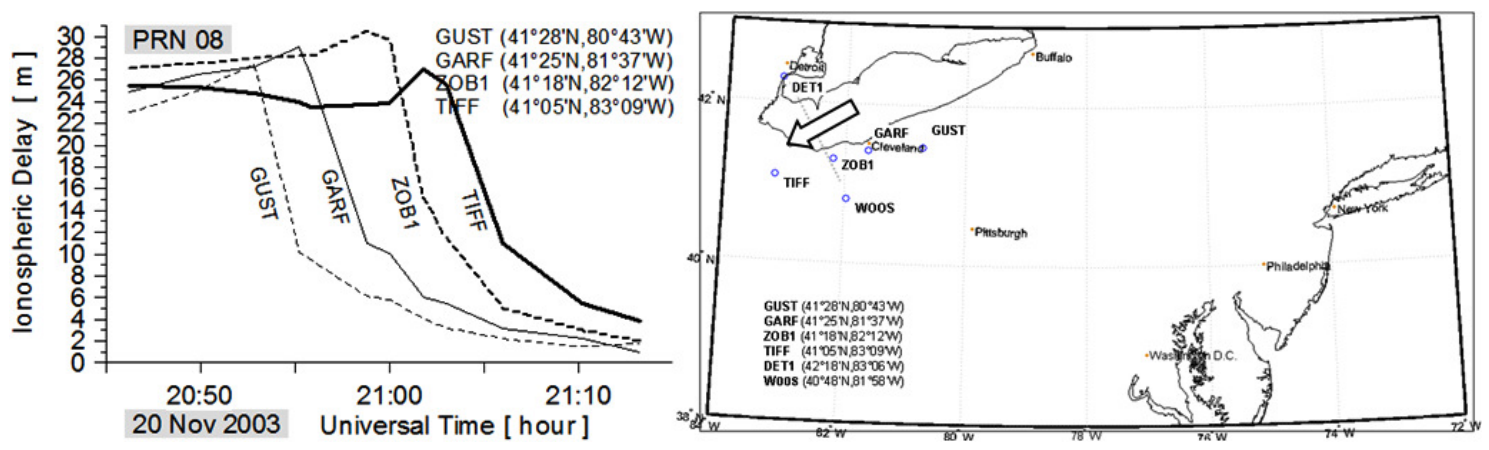

Fig.7. The geomagnetic storm on 20 November 2003. Large ionospheric delay gradients ('ionospheric walls') (left) observed among CORS clusters in the Ohio area (right). (Source: Dehel et al., 2004; US National Geodetic Survey)

As during the previous storm of 29 October, large ionospheric gradients ('ionospheric walls') (Fig.7, left) were observed among CORS clusters in the Ohio area (Fig.7, right) on 20 November 2003. The ionospheric gradient is shown crossing the station GUST, then GARF, WZOB, then TIFF (Fig.7, right). The GARF to ZOB1 gradient was estimated to be about $20 \mathrm{~m}$ in $50 \mathrm{~km}$ distance (i.e. $400 \mathrm{~mm} / \mathrm{km}$ ) and the speed of the wall was estimated at about $250 \mathrm{~m} / \mathrm{s}$ (Dehel et al., 2004). 
Similarly to the case of the 29 October 2003 storm, the available GPS observations from 20 November 2003 have been analysed. The ionospheric delay measurements deduced from all satellite links on this day are plotted in the upper panel of Fig.8, again with references to the corresponding ionospheric piercing points given in the bottom panel. The figure clearly shows the sharp increase of the ionospheric delay soon after the onset of the storm followed by a sharp decrease during the 'negative phase' of the storm. Very interesting is the period of major perturbations of the delay in the evening period between 17:00UT and 23:00UT. We will turn our attention to this particular period with the purpose of finding steep ionospheric density/delay gradients.

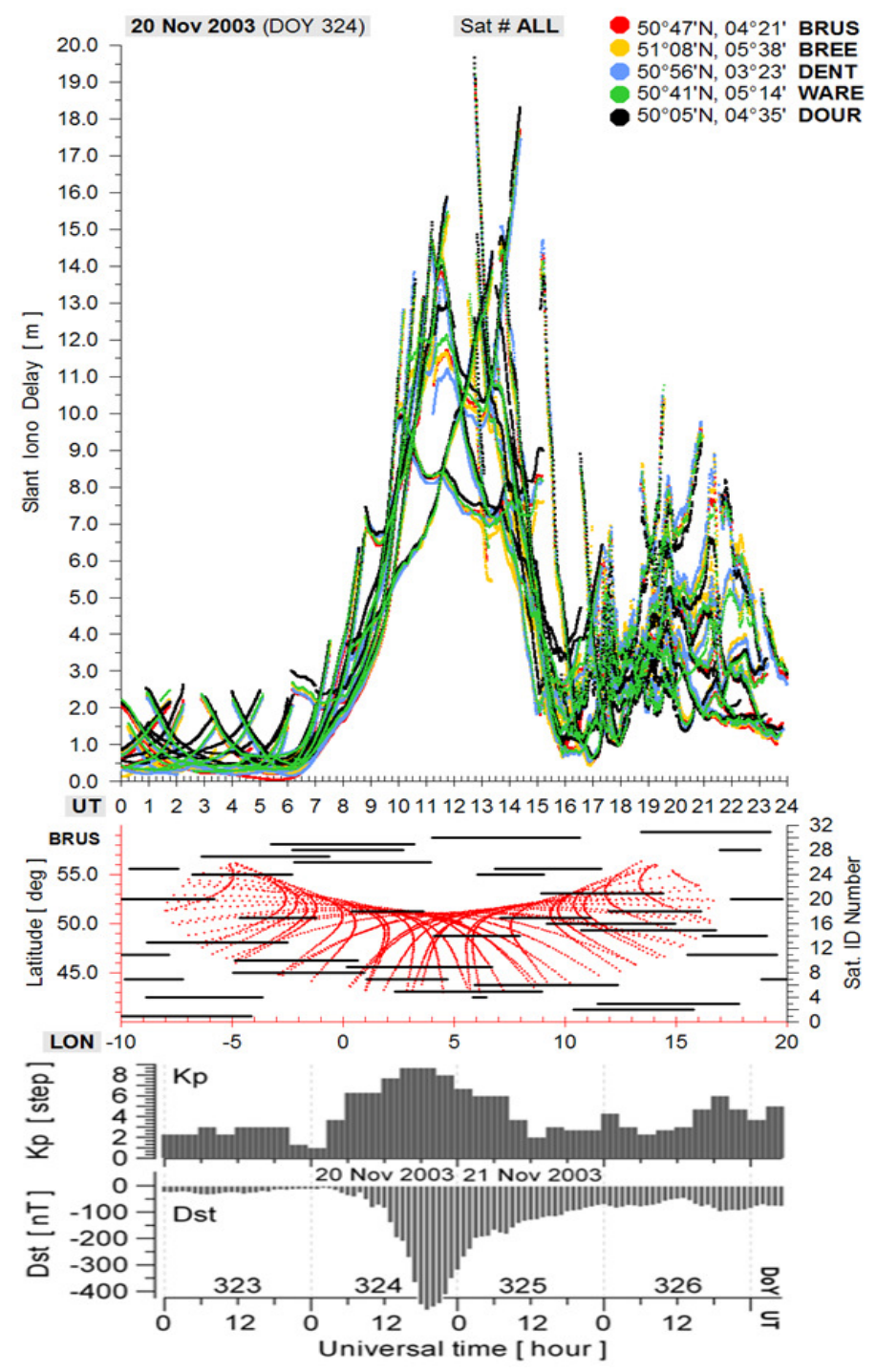

Fig.8. The geomagnetic storm on 20 November 2003. Top panel: Ionospheric delays measured via the GPS satellites 'visible' from the selected GPS stations in Belgium. Middle panel: The satellite IPP traces over Europe, with reference to the base reference station BRUS, plotted with dotted curves (red colour). The UT period of 'visibility' of each GPS satellite, again with reference to the BRUS station, plotted with solid lines (black colur). Bottom panel: The ionospheric storm background as represented by the planetary geomagnetic indices Kp and Dst.

Again, the task is complicated due to the great variability in satellite IPP trace shapes and orientations (Fig.9, left). Although the decrease of the ionospheric delay in the afternoon hour is clearly visible, the magnitude of the decrease and the speed of this decrease vary significantly from link to link. Notice how, despite the time coincidence of satellite visibility, the measurements along 
the link to satellite \#30 deviate significantly from the measurements based on other satellite links. It confirms again the importance of proper consideration of the IPP trace characteristics. As mentioned above, the attention is on the 17:00UT to 23:00UT period. The link to satellite \#15 reveals a substantial increase in the delay followed by a sharp increase about 30 minutes later (Fig.9, right). Unfortunately, the link has been closed before eventually determining whether this had been a manifestation of an ionospheric wall or not.
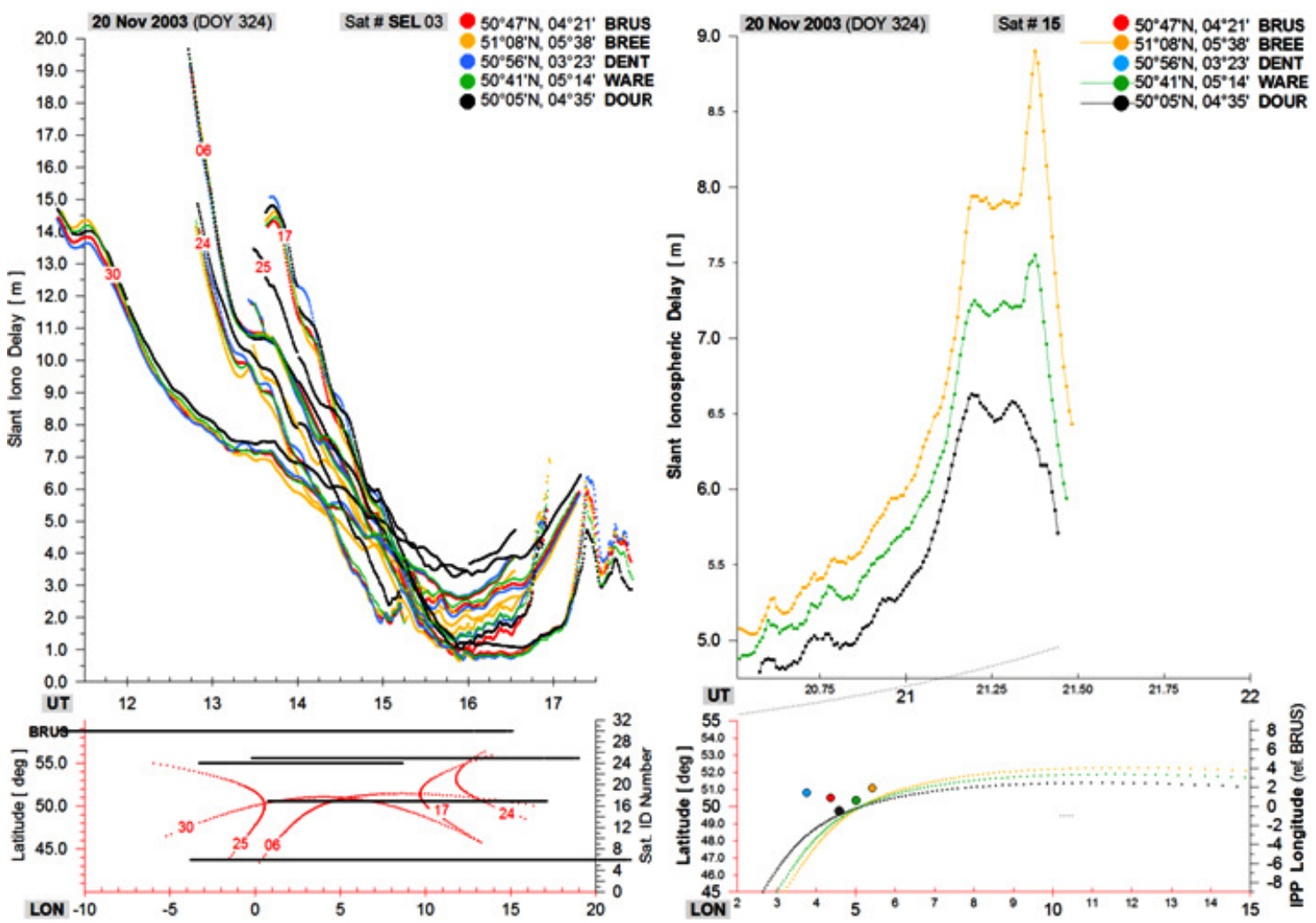

Fig.9. Top panels: Ionospheric delays during the storm of 20 November 2003 as measured via GPS satellite selection 3 (\#06, \#17, \#24, \#25, \#30) (left) and satellite \#15 (right). Bottom left panel: The satellite IPP traces, with reference to the base reference station BRUS, plotted with dotted curves (red colour) and the corresponding UT periods of GPS 'visibility' plotted with solid lines (black colour). Bottom right panel: The satellite IPP traces (colour corresponding to station) on a geographic latitude vs. longitude map (right).

Other links have been analysed for the same period and two of the links, to satellites \#11 and \#31, revealed a possible existence of a moving 'irregularity wall' (Fig.10, top panels) similar to the one observed in the American sector at approximately the same time. The walls are of relatively modest magnitude, further decreasing while travelling southward. The calculated slant TEC differences between BRUS and the other stations are consistent with the slant delay results (Fig.10, middle panels). Latitudinal gradients, appearing with opposite signs are visible on the plots for DOUR and BREE.

\section{Discussion}

It is generally accepted that the large variety of irregular ionospheric structures falls into two major categories (Davies, 1990; Hargreaves, 1992; Rawer, 1993): those produced by rapid changes of thermospheric composition (or alternatively, induced by large-scale electrodynamic drifts), and the others, well known as Travelling Ionospheric Disturbances (TIDs). Although not exclusively, ionospheric gradients showing preferences to NE-SW and SE-NW directions are known to characterize propagation of middle-scale TIDs. In this sense, it is interesting to investigate whether TIDs may also be held responsible for phenomena associated with the observed ionospheric features. 

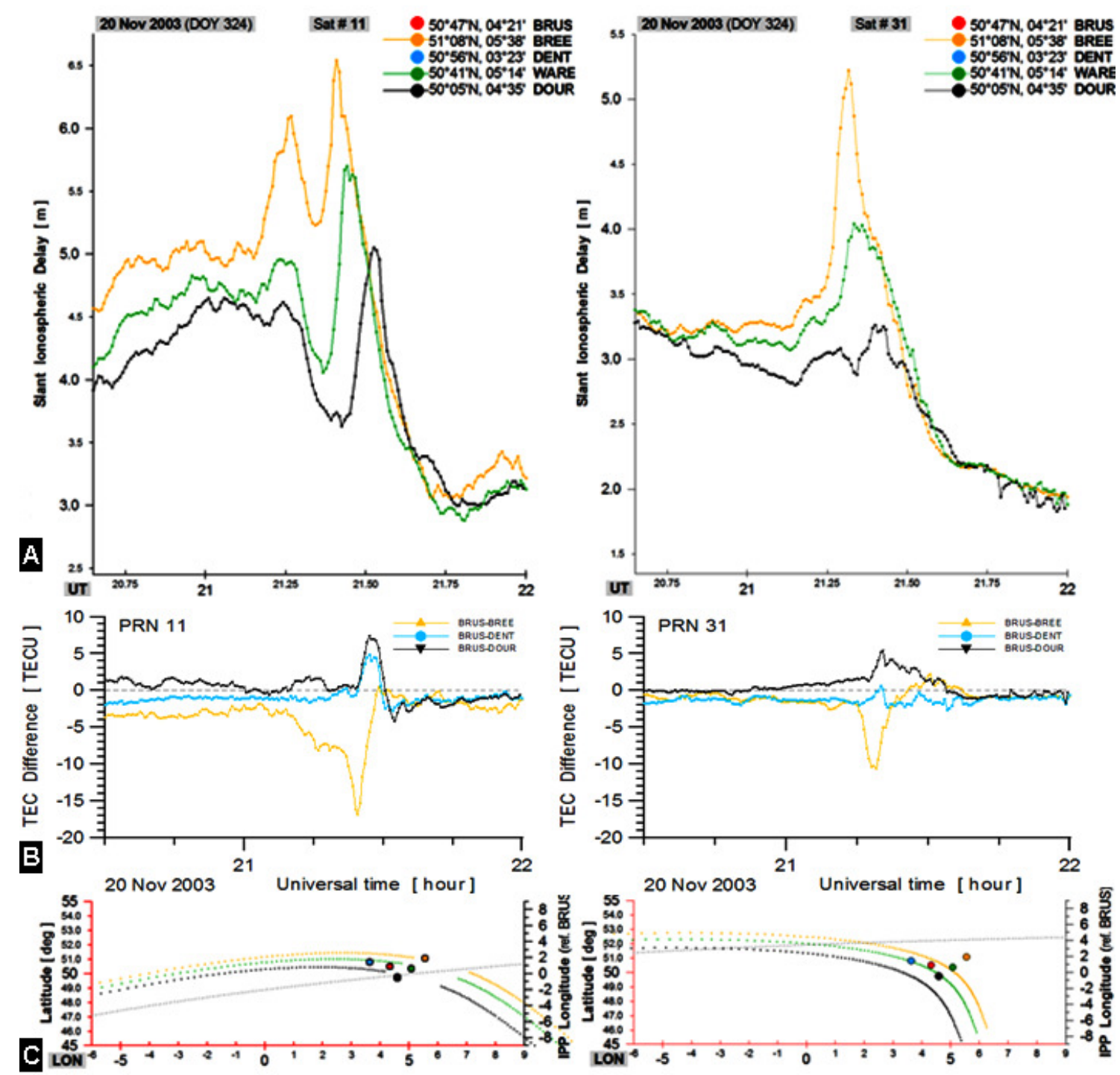

Fig.10. Top panels: Ionospheric delay gradients during the ionospheric storm of 20 November 2003 as measured via GPS satellites \#11 (left) and \#31 (right). Middle panels: Slant TEC differences between BRUS and three other stations. Bottom panels: The IPP traces (colour corresponding to station) on a geographic latitude vs. longitude map.

Another question is whether ionospheric irregularities, occurring also outside periods of geomagnetic storms, are capable of generating ionospheric features similar to those reported here. Recently, ionospheric irregularities have been estimated on a global scale by using ionospheric radio occultation (IRO) measurements and a procedure which calculates the RMS (root-mean-square) of all TEC gradients observed in each region covered during an occultation event. Thus, each RMS estimate serves as a generic measure of the ionospheric irregularity in the corresponding region of occultation. Results show that the occurrence frequency is higher during day and lower during night. Also, it has been found that the intensity of the ionospheric irregularities increases sharply during winter (Pi et al., 1997; Tsybulya and Jakowski, 2005; Stankov et al., 2006).

Regional ionospheric phenomena may also contribute to the development of large ionospheric gradients/walls. For example, the sub-auroral ionosphere at the magnetic latitudes which characterize the northeastern part of the United States may be subjected to severe ionospheric density structuring due to effects of disturbance electric fields. Systems relying on trans-ionospheric propagation need to compensate for the effects of the sharp changes in electron concentration associated with the ionospheric trough (Vo and Foster, 2001). Also, GNSS users may experience serious range accuracy 
limitations in regions where the absolute TEC values and spatial gradients are very high. Large depletions in the ionospheric density during post-sunset periods at equatorial latitudes are known to cause scintillation effects and reduce SBAS system availability (Klobuchar et al., 2002).

There is also a methodological issue concerning the research of the ionospheric anomaly phenomena. The approach used here required exhaustive automated and manual analysis with due consideration of various details such as the ground station locations, the shape and orientation of the satellite IPP traces. The task itself is quite demanding and prone to omissions and misinterpretation of some observations. For better results, it will be necessary to adopt more sophisticated, ray tracing algorithms (e.g. Strangeways, 2000; and the references therein).

Further automation of the data processing and analysis is also a must. Since the ionospheric delay is directly proportional to the total electron content value, high-quality TEC monitoring/mapping can also be utilized for the purpose (e.g. Jakowski et al., 2005; Stankov et al., 2006). On the one hand, the TEC mapping provides opportunities for covering larger areas thus allowing for easier detection and analysis of dynamic ionospheric structures. On the other hand, since TEC values at grid points are mostly obtained by interpolating between measured values, TEC gradients obtained in this way may smooth out the real gradients and thus deem the interpretation incorrect. Therefore, the TEC mapping should be made with a very high spatial and temporal resolution, and for aircraft navigation purposes, it should be provided in real time. Real-time reconstruction of the vertical ionospheric density distribution via simultaneous GNSS and digital ionosonde measurements (Stankov et al., 2003, 2005), can also be utilized, e.g. for map verification purposes or for ionospheric slab thickness estimation. The latter can provide valuable clues about the local depth of the ionosphere that may in turn help the estimation of the maximum ionospheric delay and the ionospheric threat modelling in general (Blanch et al., 2001). Short-term forecasting of the ionospheric parameters (e.g. Houminer and Soicher, 1996; Muhtarov and Kutiev, 1999; Stankov et al., 2004) is also a key instrument in the ionospheric effects mitigation.

It is therefore expected that the combined use of diverse observation techniques and the utilization of complex monitoring/modeling approaches would bring more reliable results in mitigating the effects of the ionospheric gradients.

\section{Conclusions}

TEC and ionospheric delay measurements, performed in Belgium during the geomagnetic storms of 29 October 2003 and 20 November 2003, have been analysed in search of anomalous moving ionospheric walls similar to those reported for the United States. It has been found that such similar ionospheric delay gradients did occur in Europe during these storms, although they were not so pronounced as in the American sector. Further research is needed, with available data from other geomagnetic storm events, in order to analyse this interesting phenomenon. In particular, it remains to be investigated whether ionospheric effects of such scale/nature are due to concrete ionospheric conditions that developed during these events only or, in general, the local ionosphere conditions in US are more susceptible to such phenomena. In this sense, one important objective should be to assess the integrity risk to GBAS/SBAS services and thus to determine if additional protection is needed for GNSS-based aircraft navigation in Europe.

\section{Acknowledgements}

This research is supported by the Royal Meteorological Institute of Belgium via grant GJU/06/2423/CTR/GALOCAD and the RMI Centre of Excellence.

\section{References}

Akasofu, S.I., Chapman, S. Solar-Terrestrial Physics. Oxford University Press, Oxford, UK, 901 pages, 1972.

Blanch, J., Walter, T., Enge, P. Ionospheric threat model methodology for WAAS. in: Proceedings of the ION Annual Meeting, June 2001, Albuquerque NM, pp. 508-513, 2001. 
Braff, R. Description of the FAA's Local Area Augmentation System (LAAS). Navigation, 44(4), 411-424, 1998.

Datta-Barua, S., Walter, T., Pullen, S., Luo, M., Blanch, J., Enge, P. Using WAAS ionospheric data to estimate LAAS short baseline gradients. in: Proceedings of the ION National Technical Meeting, January 28-30, 2002, San Diego CA, pp. 523-531, 2002.

Davies, K. Ionospheric Radio. Peter Peregrinus Ltd., London, UK, 1990.

Dehel, T., Lorge, F., Warburton, J., Nelthropp, D. Satellite navigation vs. the ionosphere: where are we, and where are we going? in: Proceedings of the ION GNSS, September 21-24, 2004, Long Beach CA, pp. 375-386, 2004.

Federal Aviation Administration (FAA). Specification for the Wide Area Augmentation System (WAAS). Document DTFA01-96-C-00025 Modification No. 0111 / FAA-E- 2892b Change 2 (August 13, 2001), US Department of Transportation, 2001.

Fuller-Rowell, T.J., Codrescu, M.V., Moffett, R.J., Quegan, S. Response of the thermosphere and ionosphere to geomagnetic storms. Journal of Geophysical Research, 99(3), 3893-3914, 1994.

Fuller-Rowell, T.J., Codrescu, M.V., Rishbeth, H., Moffett, R.J., Quegan, S. On the seasonal response of the thermosphere and ionosphere to geomagnetic storms. Journal of Geophysical Research, 101(2), 2343-2353, 1996.

Hargreaves, J.K. The Solar-Terrestrial Environment, Cambridge University Press, Cambridge, 1992.

Hofmann-Wellenhof, B., Lichtenegger, H., Wasle E. GNSS-Global Navigation Satellite Systems: GPS, GLONASS \& more, Springer, Vienna New York, 516 pages, 2008.

Houminer, Z., Soicher, H. Improved short-term predictions of $f_{0} F_{2}$ using GPS time delay measurements. Radio Science, 31(5), 1099-1108, 1996.

Jakowski, N., Stankov, S.M., Klaehn, D. Operational space weather service for GNSS precise positioning. Annales Geophysicae, 23(9), 3071-3079, 2005.

Jodogne, J.C., Stankov, S.M. Ionosphere-plasmasphere response to geomagnetic storms studied with the RMI-Dourbes comprehensive database. Annals of Geophysics, 45(5), 629-647, 2002.

Klobuchar, J.A., Ionospheric Effects on GPS. in: Parkinson, B.W., Spilker, J.J. Jr. (Eds.), Global Positioning System: Theory and Application, American Institute of Aeronautics and Astronautics, Vol. 164. Washington, DC, pp. 485-515, 1996.

Klobuchar, J. A., Doherty, P., El-Arini, M.B., Lejeune, R., Dehel, T. Total Electron Content Effects on GNSS Augmentation System. in: Proceedings of the XXVIIth URSI General Assembly, Maastricht, 2002.

Konno, H., Pullen, S., Rife, J., Enge, P. Evaluation of two types of dual-frequency differential GPS techniques under anomalous ionosphere conditions. in: Proceedings of the ION National Technical Meeting, January 18-20, 2006, Monterey CA, vol.2, pp. 735-747, 2006.

Leitinger, R. Ionospheric Electron Content. in: Dieminger, W., Hartmann, G.K., Leitinger, R. (Eds.), The upper atmosphere - data analysis and interpretation. Springer, Berlin, pp. 660-672, 1996.

Luo, M., Pullen, S., Akos, D., Xie, G., Datta-Barua, S., Walter, T., Enge, P. Assessment of ionospheric impact on LAAS using WAAS supertruth data. in: Proceedings of the ION Annual Meeting, June 24-26, 2002, Albuquerque NM, pp. 175-186, 2002.

Luo, M., Pullen, S., Dennis, J., Konno, H., Xie, G., Walter, T., Enge, P., Datta-Barua, S., Dehel, T. LAAS Ionosphere Spatial Gradient Threat Model and Impact of LGF and Airborne Monitoring. in: Proceedings of the ION GPS, September 9-12, 2003, Portland, OR, pp. 2255-2274, 2003.

Luo, M., Pullen, S., Ene, A., Qiu, D., Walter, T., Enge, P. Ionospheric threat to LAAS: updated model, user impact, and mitigations. in: Proceedings of the ION GNSS, September 21-24, 2004, Long Beach, CA, pp. 2771-2785, 2004.

Muhtarov, P., Kutiev, I. Autocorrelation method for temporal interpolation and short-term prediction of ionospheric data. Radio Science, 34(2), 459-464, 1999.

Pi, X., Mannucci, A.J., Lindqwister, U.J., Ho, C.M. Monitoring of Global Ionospheric Irregularities Using the Worldwide GPS Network. Geophysical Research Letters, 24, 2283, 1997.

Proelss, G.W. On explaining the local time variation of ionospheric storm effects. Annales Geophysicae, 11(1), 1-9, 1993.

Rawer, K. Wave Propagation in the Ionosphere. Kluwer Academic, Dordrecht Boston, 486 pages, 1993. 
Stankov, S.M., Jakowski, N., Heise, S., Muhtarov, P., Kutiev, I., Warnant, R. A new method for reconstruction of the vertical electron density distribution in the upper ionosphere and plasmasphere. Journal of Geophysical Research, 108(A5), 1164, 2003.

Stankov, S.M, Kutiev, I.S., Jakowski, N., Wehrenpfennig, A. GPS TEC forecasting based on autocorrelation analysis. Acta Geodaetica et Geophysica Hung., 39(1), pp. 1-14, 2004.

Stankov, S.M., Jakowski, N., Heise, S. Reconstruction of ion and electron density profiles from spacebased measurements of the upper electron content. Planetary and Space Science, 53(9), 945-957, 2005.

Stankov, S.M., Jakowski, N., Tsybulya, K., Wilken, V. Monitoring the generation and propagation of ionospheric disturbances and effects on GNSS positioning. Radio Science, 41(5), RS6S09, 2006.

Stankov, S.M., Jakowski, N. Ionospheric effects on GNSS reference network integrity. Journal of Atmospheric and Solar-Terrestrial Physics, 69(4-5), 485-499, 2007.

Strangeways, H.J. Effect of horizontal gradients on ionospherically reflected or transionospheric paths using a precise homing-in method. Journal of Atmospheric and Solar-Terrestrial Physics, 62(15), 1361-1376, 2000.

Szuszczewicz, E.P., Lester, M., Wilkinson, P., Blanchard, Abdu, M., Hanbaba, R., Igarashi, K., Pulinets, S., Reddy, B.M. A comparative study of global ionospheric responses to intense magnetic storm conditions, Journal of Geophysical Research, 103(A6), 11665-11684, 1998.

Tsybulya, K., Jakowski, N. Medium- and small-scale ionospheric irregularities detected by GPS radio occultation method, Geophysical Research Letters, 32, L09103, 2005.

Ventura-Traveset, J., Flament, D. (Eds.) EGNOS - The European Geostationary Navigation Overlay System - A Cornerstone of Galileo. European Space Agency, ESA SP-1303, 2007.

Vo, H.B., Foster, J.C. A quantitative study of ionospheric density gradients at midlatitudes. Journal of Geophysical Research, 106(A10), 21555-21563, 2001.

Walter, T., Hansen, A., Blanch, J., Enge, P., Mannucci, A., Pi, X., Sparks, L., Iijima, B., El-Arini, B., Lejeune, R., Hagen, M., Altshuler, E., Fries, R., Chu, A. Robust Detection of Ionospheric Irregularities. Navigation, 48(2), 89-100, 2001.

Warnant, R., Pottiaux, E. The increase of the ionospheric activity as measured by GPS. Earth Planets and Space, 52(11), 1055-1060, 2000. 